\title{
Os coletivos de pensamento na formação de professores de Biologia
}

\author{
The collectives of thinking in the formation of teachers of Biology
}

\author{
Eloiza Aparecida Silva Ávila de Matos* \\ Rodrigo Diego de Souza*
}

\section{Resumo}

\begin{abstract}
A organização curricular das licenciaturas também consiste num espaço de formação, pois delineiam os trajetos curriculares pelos quais os licenciados são inicialmente formados. Dessa forma, o objetivo deste artigo é caracterizar os possíveis coletivos de pensamento que estão presentes na formação dos professores de Biologia. O referencial teórico que pauta a discussão é a epistemologia de Ludwik Fleck. Os procedimentos utilizados neste estudo compreendem a pesquisa documental apoiada por técnicas de pesquisa qualitativa, com a contribuição das categorias de Fleck. Analisou-se o Projeto Pedagógico da Licenciatura em Ciências Biológicas de uma universidade pública do estado do Paraná e constatou-se: a existência de possíveis coletivos de pensamento na formação dos professores de Biologia, os quais se movimentam por meio de instauração, extensão e transformação dos estilos de pensamento no interior dos coletivos; a importância das complicações no processo de instauração de um novo estilo de pensamento. Além disso, evidenciam-se as lacunas presentes nas disciplinas que compõem a área de educação em ciências, o que indica a necessária reflexão acerca de que professor se espera formar e da importância das discussões relacionadas à educação e ao ensino para a efetivação da identidade das licenciaturas, e não bacharelados mascarados de licenciaturas.
\end{abstract}

Palavras-chave: Coletivos de pensamento. Educação em ciências. Licenciaturas. Professores de Biologia.

\section{Abstract}

The curricular organization of the degrees also consists of a training space, as they outline the curricular paths by which the graduates are initially trained, In this way, the objective of this article is to characterize the possible collectives of thought that are present in the training of Biology teachers. The theoretical framework that guides the discussion is the Epistemology of Ludwik Fleck. The procedures used in this study are documentary research supported by qualitative research techniques, with the contribution of the Fleck categories. The Pedagogical Project of the Degree in Biological Sciences of a Public University of the State of Paraná was analyzed, and it was verified: the existence of possible collectives of thought that are present in the training of Biology teachers, which move through the establishment, extension and transformation of the Thought Styles within the Collectives; the importance of complications in the process of instituting a new Style of Thought; the gaps in the disciplines that compose the area of Science Education are evidenced, which indicates to the necessary reflection about which teacher is expected to form, and the importance of the discussions related to Education and Teaching for the realization of the identity of the Degree.

Keywords: Thought collectives. Education in sciences. Bachelor's degrees. Teachers of Biology.

Recebido em 13/10/2017 - Aprovado em 10/01/2018

http://dx.doi.org/10.5335/rep.v25i2.8158

Doutora em Educação pela Universidade Metodista de Piracicaba. Docente do Programa de Pós-Graduação em Ensino de Ciência e Tecnologia e professora da Universidade Tecnológica Federal do Paraná - Campus de Ponta Grossa. E-mail: elomatos@utfpr.edu.br

** Doutorando em Educação Científica e Tecnológica na Universidade Federal de Santa Catarina. E-mail: diego_souzasmd@ yahoo.com.br 


\section{Introdução}

Refletir sobre a formação dos professores de Biologia, em uma sociedade em constante avanço científico e tecnológico, engloba as discussões acerca dos espaços de formação. Compreende-se que a organização curricular das licenciaturas consiste em um espaço de formação, pois delineia os trajetos curriculares pelos quais os licenciados são formados, considerando-se que a formação inicial não é o único espaço de formação, já que, durante toda a sua trajetória profissional, os docentes estão permeados de outros momentos de formação continuada em serviço ou individual.

Neste artigo, não se pretende discutir sobre o currículo e a organização curricular das licenciaturas, pois não se esgotariam as reflexões atreladas a tal temática, contudo, tem-se o objetivo de caracterizar os possíveis coletivos de pensamento que estão presentes na formação dos professores de Biologia. Este texto emerge de uma pesquisa de mestrado desenvolvida no Programa de Pós-Graduação em Ensino de Ciência e Tecnologia da Universidade Tecnológica Federal do Paraná, pautada no referencial teórico do médico e filósofo polonês Ludwik Fleck (1896-1961).

Inicialmente, apresentam-se as principais categorias de Fleck e, posteriormente, a análise da matriz curricular de um curso de licenciatura em Ciências Biológicas de uma universidade pública do estado do Paraná. Para a organização dos dados, foram utilizadas técnicas de pesquisa qualitativa (FLICK, 2009), com a contribuição para a análise a partir das categorias de Fleck: coletivos de pensamento; instauração, extensão e transformação de estilos de pensamento; complicações; harmonia de ilusões, entre outras.

\section{A teoria dos coletivos de pensamento}

Conhecer, para Ludwik Fleck, significa, em primeiro lugar, que o conhecimento não é neutro, mas uma constatação dos resultados inevitáveis do processo de conhecer sob determinadas condições dadas. As condições dadas no referencial fleckiano correspondem à relação do sujeito e do objeto na realidade em que estão inseridos por acoplamentos passivos (conexões passivas), os quais são o resultado do que é percebido como realidade objetiva, e por acoplamentos ativos (conexões ativas), que significam o saber que pertence ao coletivo no qual o processo de conhecimento acontece (FLECK, 2010).

Nesse processo, o ato da constatação compete a três fatores que participam do processo de conhecimento; o indivíduo, o coletivo e a realidade objetiva, como afirma Fleck: 
Aquilo que pensa no homem não é ele, mas sua comunidade social. A origem do seu pensamento não está nele, mas no meio social onde vive, na atmosfera social na qual respira, e ele não tem como pensar de outra maneira a não ser daquela que resulta necessariamente das influências do meio social que se concentram no seu cérebro (2010, p. 90).

Nessa perspectiva, a construção do conhecimento não parte apenas do sujeito para o objeto com as implicações da intencionalidade, como apresentara a fenomenologia, mas o objeto é contextualizado, historicamente situado, sofre as implicações do ver formativo do sujeito e das vivências que ele traz em sua história, e é compartilhado de acordo com um estilo de pensamento vigente.

Fleck institui as características que possibilitam definir um estilo de pensamento, e Cutolo (2001) organiza as definições propostas por Fleck (2010) para caracterizar o estilo de pensamento, conforme a seguir:

1- modo de ver, entender e conceber; 2- processual, dinâmico, sujeito a mecanismos de regulação; 3- determinado psico/socio/histórico/culturalmente; 4- que leva a um corpo de conhecimentos e práticas; 5- compartilhado por um coletivo com formação específica (CUTOLO, 2001, p. 55).

Nesse sentido, evidencia-se a identidade do estilo de pensamento como práticas e conhecimentos compartilhados por um grupo de indivíduos, pois o estilo de pensamento instaura-se em um coletivo de pensamento, o qual passa a ser extensivo a diversos sujeitos, possibilitando compreender o tráfego dos sujeitos por diversos coletivos de pensamento.

O estudo de Gonçalves, Marques e Delizoicov (2007) apresenta considerações sobre as relações entre os estilos de pensamento e os coletivos de pensamentos na formação de professores e pesquisadores em química:

Em outras palavras, o estilo de pensamento pode ser caracterizado como práticas e conhecimentos compartilhados. Quando um determinado estilo de pensamento é compartilhado por um grupo de indivíduos, esse grupo é denominado coletivo de pensamento (FLECK, 1986). Um sujeito pode pertencer a distintos coletivos de pensamento simultaneamente. Um pesquisador em Química, por exemplo, pode se reportar a outros coletivos de pensamento como o de pesquisadores em ensino de Química, ou mesmo ao de professores de Química, e assim por diante. Para Fleck (1986), durante a dinâmica de produção de conhecimento, o coletivo de pensamento se estratifica em círculos: esotérico (especialistas) e exotérico (leigos e leigos formados). Contudo, pertencer a um círculo esotérico ou exotérico é uma questão relativa. Cabe destacar, ainda, que a noção de círculo esotérico e exotérico depende da presença de mais de um coletivo de pensamento (2007, p. 5).

Para compreender o processo de circulação de ideias e práticas entre os distintos coletivos de pensamento, faz-se necessário remeter-se à formação do estilo de pensamento, a qual ocorre em um processo de circulação de ideias e práticas nos círculos hierarquizados epistemologicamente: um círculo menor esotérico, consti- 
tuído pelos especialistas de uma área, e um círculo maior exotérico, formado pelos participantes do coletivo de pensamento (FLECK, 2010). Como constatado anteriormente, os sujeitos podem pertencer a vários coletivos simultaneamente e atuam como transmissores de ideias entre os coletivos (PFUETZENREITER, 2003).

$\mathrm{O}$ tráfego de ideias nos círculos hierarquizados epistemologicamente também ocorre entre os círculos esotérico e exotérico, sendo o primeiro constituído pelos especialistas de determinada área, que fundamentam e estabelecem critérios fixos para este saber, o qual será disseminado e popularizado para o interior de um coletivo de pensamento ou para diversos coletivos de pensamento, caracterizam uma circulação intercoletiva, do esotérico para o exotérico, o qual é constituído pelos participantes de um coletivo de pensamento que não seja o mesmo do esotérico (TOLENTINO; ROSSO, 2011).

Delizoicov, Carneiro e Delizoicov (2004) também afirmam que o processo de troca de ideias nos coletivos de pensamento ocorre por meio de circulações intra e intercoletivas. A circulação intracoletiva ocorre no interior de um coletivo de pensamento com o intuito de formação dos pares, já a circulação intercoletiva consiste na disseminação e na popularização dos estilos de pensamento, que podem ocorrer no interior de um coletivo ou entre distintos coletivos de pensamento.

Por fim, em processos de instauração, extensão e transformação de estilos de pensamento nos coletivos, observa-se a construção de um novo fato científico, sendo necessária a circulação das ideias e práticas que compõem determinado coletivo de pensamento para a manutenção desse estilo de pensamento compartilhado pelo coletivo (DA ROS, 2000; CUTOLO, 2001; FLECK, 2010).

Observando-se certa coercitividade do estilo de pensamento, a capacidade que este sistema fechado de ideias apresenta de coagir e determinar o pensamento dos sujeitos, por meio da circulação inter e intracoletiva de ideias e práticas, quando o círculo esotérico externaliza suas ideias fechadas para o exotérico (MELZER, 2011; TOLENTINO; ROSSO, 2011). Desse modo, os estilos de pensamento condicionam os diferentes coletivos de pensamentos, como afirmam Delizoicov et al.:

O estilo de pensamento no qual o indivíduo foi inserido, segundo Fleck, passa a mediar a relação sujeito objeto, exercendo certa coerção no observar, permitindo um ver formativo, direto e desenvolvido. Essa coerção de pensamento faz com que os membros de um coletivo venham a rejeitar, a reinterpretar os fatos que contradizem os pressupostos que embasam o estilo de pensamento dominante (2002, p. 63).

A manutenção do estilo de pensamento vigente acena para o que Fleck denomina como harmonia de ilusões, quando a estabilização de um estilo de pensamento promove a estruturação de uma harmonia das ilusões, um sistema de opinião elaborado e fechado, constituído de muitos detalhes e relações, que persiste 
continuamente diante de tudo, até que suscitem complicações que desestabilizem as verdades postas e, com o conjunto de complicações, constate-se a emergência de um novo fato científico, historicamente situado (FLECK, 2010; CUTOLO, 2001).

Para Fleck, várias descobertas científicas partem de pressuposições falsas, primeiros experimentos irreprodutíveis, erros e desvios; o que reforça a impossibilidade de uma autoria individual de qualquer conhecimento e fato científico, apontando a vigência de uma autoria que é do coletivo e dos costumes desse determinado grupo (FLECK, 2010; CUTOLO, 2001).

Nesse processo, ao apresentar o conceito de fato científico como uma relação de conceitos conforme o estilo de pensamento vigente, ressaltam-se as inúmeras vezes em que Fleck refere-se à Gestalt em sua obra, segundo ele, o mais importante na efetivação de um novo estilo de pensamento é a disposição da percepção dos sujeitos direcionada para o mais importante do estilo de pensamento, algo que, para ele, é possivelmente explicado pela Gestalt (FLECK, 2010; ALVES, 2012). Como aponta Fleck:

Assim nasce o fato: primeiro um sinal de resistência no pensamento inicial caótico, depois uma certa coerção do pensamento e, finalmente, uma forma (Gestalt) a ser percebida de maneira imediata. Ele sempre é um acontecimento que decorre das relações na história do pensamento, sempre é resultado de um determinado estilo de pensamento (2010, p. 144-145).

A análise em torno do fato científico é um processo definitivamente coletivo, longo e extremamente marcado pelas impressões da comunidade científica que o produziu e que abarca todo o conhecimento, as quais não deixam de ser parciais e dependentes do tempo e da cultura em que foram estabelecidas.

As ideias centrais de Fleck se fundamentam, segundo Delizoicov et al. (2002), na perspectiva de que os fatos científicos são condicionados e explicados socio-historicamente e as teorias científicas do presente estão relacionadas com as do passado, e estas se ligarão às do futuro.

Contribui para as discussões levantadas por Fleck a leitura piagetiana da sociogênese do conhecimento (que muitas vezes passa despercebida nos estudos acerca de Piaget). Piaget e García (2011), na obra Psicogênese e história das ciências, apresentam as relações entre a sociologia da ciência e a sociogênese do conhecimento, um resgate histórico e crítico dos apontamentos dos epistemólogos, sua relevância e suas proposições para reformulações acerca da epistemologia.

Piaget e García (2011) evidenciam que a cada momento histórico e em cada sociedade predomina um quadro epistêmico, produto das configurações sociais, que é a origem de novos pressupostos epistêmicos. Nesse aspecto, percebe-se a capacidade ideologizante da ciência, quando as características de determinada sociedade moldam o tipo de ciência a ser desenvolvido. 
Diante do exposto, as relações entre os coletivos de pensamento, a harmonia de ilusões, a instauração, a extensão e a transformação de estilos de pensamento, por meio das circulações de conhecimentos e das práticas nos círculos esotéricos e exotéricos, e a emergência de um novo fato científico que enfrente as complicações da realidade, acontecem no estado de conhecimento, no qual o processo de construção do saber acontece entre os indivíduos, o coletivo e a realidade objetiva, por meio dos acoplamentos ativos e passivos (conexões ativas e passivas).

Fleck sustenta que a construção de conhecimento não deve apenas considerar a relação bilateral entre sujeito e objeto, mas deve considerar o estado de conhecimento como um terceiro componente dessa relação, para ligar o conhecimento ao conhecer, como se apresentou no início deste tópico, ao abordar as conexões ativas e passivas, conforme a Figura 1 apresenta:

Figura 1 - A relação sujeito e objeto no estado de conhecimento

2

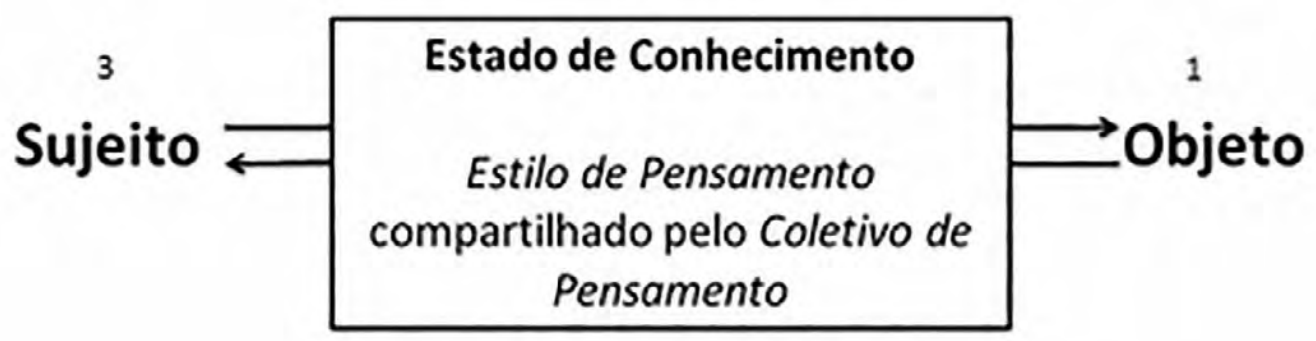

Fonte: elaboração dos pesquisadores a partir de anotações durante as aulas do professor doutor Demétrio Delizoicov, no PPGECT da Universidade Federal de Santa Catarina, no ano de 2014.

Conclui-se que o conhecimento é construído coletivamente, situado historicamente, com uma formação a partir da singularidade histórica de um pensamento que se transforma justamente em virtude da particularidade das forças coletivas, em um conhecimento que se repete, critica e se constrói, e que, portanto, apresenta-se como objetivo e real (FLECK, 2010; DA ROS, 2000).

O pensamento de Fleck, devidamente delineado, permite fazer uma leitura da formação dos professores de Biologia a partir do papel formativo dos coletivos de pensamento nas licenciaturas e das implicações disso. 


\section{Os possíveis coletivos de pensamento que permeiam a formação de professores de Biologia}

Os pressupostos da epistemologia de Fleck apresentam possibilidades para uma maior compreensão das implicações socio-históricas que permeiam a formação do professor de Biologia, por isso, pensar o processo de formação de professores permite-nos identificar os possíveis coletivos de pensamento que permeiam a formação.

Ao tratar sobre os possíveis coletivos de pensamento, utiliza-se o termo "possíveis" para os coletivos, pois se pensa apenas na possibilidade de demonstrar que as relações apresentadas são caracterizadas como coletivos de pensamentos pelos quais os licenciandos circulam e que implicam em sua formação.

Vale ressaltar que, ao optar por indicar possíveis coletivos de pensamento, tem-se em mente a complexidade que permeia o ato de indicar coletivos de pensamento e estilos de pensamento, haja vista que, no interior de um coletivo de pensamento, existem, segundo Fleck (2010), sujeitos que também compartilham de inúmeros e distintos estilos de pensamento que, direta ou indiretamente, circulam no interior do coletivo.

Nesse sentido, para análise, foram sistematizados os dados coletados nas Diretrizes Curriculares para os Cursos de Ciências Biológicas (BRASIL, 2001, 2002) e no Projeto Pedagógico do Curso de Licenciatura em Ciências Biológicas (PPC-LicBio) de uma universidade pública do estado do Paraná.

O PPC-LicBio da universidade estadual e pública na qual os sujeitos da pesquisa estão matriculados e frequentam regularmente apresenta o currículo pleno do curso superior de graduação em licenciatura em Ciências Biológicas, com o total mínimo equivalente a 3.362 horas, sendo 680 horas em disciplinas de formação básica geral, 2.006 horas em disciplinas de formação específica profissional, 68 horas em disciplinas de diversificação ou aprofundamento, 408 horas de estágio supervisionado e 200 horas de atividades complementares, distribuídas em, no mínimo, 4 anos e, no máximo, 6 anos letivos.

Torna-se relevante a análise do currículo pleno do curso para compreender as circulações de conhecimentos e práticas dos sujeitos da pesquisa com a realidade objetiva em que estão imersos, pois eles constroem os saberes no estado de conhecimento mediado por esse currículo e pelos diversos fatores que o determinam, conforme Sacristán afirma: 
Os currículos são a expressão do equilíbrio de interesses e forças que gravitam sobre o sistema educativo num dado momento, enquanto que através deles se realizam os fins da educação no ensino escolarizado. [...]. O currículo, em seu conteúdo e nas formas através das quais se nos apresenta e se apresenta aos professores e aos alunos, é uma opção historicamente configurada, que se sedimentou dentro de uma determinada trama cultural, política, social e escolar; está carregado, portanto, de valores e pressupostos que é preciso decifrar (2000, p. 17).

A leitura da afirmação de Sacristán (2000, p. 17) sobre o currículo sinaliza profundamente para o referencial fleckiano, na medida em que os valores e os pressupostos que compõem a "trama cultural, política, social e escolar" são determinados pela realidade objetiva e por estilos de pensamento vigentes que instauram possíveis coletivos de pensamento.

Inicia-se a análise do ementário do PPC-LicBio com a apresentação das disciplinas de formação básica geral e de estágio, conforme a Figura 2.

Figura 2 - Disciplinas de formação básica geral e estágio do PPC-LicBio

\section{DISIPLINAS DE FORMAÇÄO BÁSICA GERAL}

1 Educaçăo e Ciências Biológicas

2 Educaçăo
1.1 - Laboratório de Ensino em Ciências e Biologia I

1.2 - Laboratório de Ensino em Ciências e Biologia II

1.3 - Laboratório de Ensino em Ciências e Biologia III

1.4 - Laboratório de Ensino em Ciências e Biologia IV

1.5 - Lingua Brasileira de Sinais - LIBRAS

2.1 - Psicologia da Educaçăo

2.2 - Fundamentos da Educaçăo

2.3 - Estrutura e Funcionamento da Educação Básica

2.4 - Didática

\section{DISCIPLINAS DE ESTÁGIO SUPERVISINADO}

2 Educaçăo
2.5 - Estágio Curricular Supervisionado I

2.6 - Estágio Curricular Supervisionado II

Fonte: PPC-LicBio, 2015.

Observam-se, na Figura 2, bem delineados, os possíveis coletivos de pensamento da educação e do ensino de Ciências e Biologia, entretanto, para uma maior compreensão dessas disciplinas enquanto pertencentes a coletivos de pensamento e suas implicações na formação de professores de Biologia, buscou-se analisar as ementas das disciplinas de Laboratório de Ensino de Ciências e Biologia I, II, III e IV, e a ementa da disciplina de Didática, com o intuito de investigar as possíveis 
contribuições dos componentes curriculares dessas disciplinas para o ver formativo dos licenciandos. Optou-se por não discutir as questões referentes ao estágio supervisionado neste trabalho, o que poderá ser aprofundado em trabalhos futuros. No Quadro 1, apresentam-se as ementas das disciplinas analisadas.

Quadro 1 - Ementário das disciplinas de Laboratório de Ensino (I, II, III e IV) e Didática

\begin{tabular}{|c|c|c|}
\hline Disciplinas & Ementas & $\begin{array}{l}\text { Carga } \\
\text { horária }\end{array}$ \\
\hline $\begin{array}{l}\text { Laboratório de Ensino de } \\
\text { Ciências e Biologia I }\end{array}$ & $\begin{array}{l}\text { Contextualização do conhecimento disponibilizado nas disciplinas } \\
\text { da } 1^{\text {a }} \text { série do curso. Desenvolvimento de habilidades e compe- } \\
\text { tências relativas ao trabalho docente. Atividades de ação-reflexão- } \\
\text {-ação na prática educativa diante das atividades propostas pelas } \\
\text { disciplinas específicas. Iniciação à metodologia científica. Visita } \\
\text { técnica. Evento de Extensão em Ensino de Ciências e Biologia } \\
\text { em espaço formal de ensino. Mostra do Laboratório de Ensino em } \\
\text { Ciências e Biologia. }\end{array}$ & $102 \mathrm{~h}$ \\
\hline $\begin{array}{l}\text { Laboratório de Ensino de } \\
\text { Ciências e Biologia II }\end{array}$ & $\begin{array}{l}\text { Contextualização do conhecimento disponibilizado nas disciplinas } \\
\text { da } 2^{\underline{a}} \text { série do curso. Desenvolvimento de habilidades e compe- } \\
\text { tências relativas ao trabalho docente. Atividades de ação-reflexão- } \\
\text {-ação na prática educativa diante das atividades propostas pelas } \\
\text { disciplinas específicas. Seminários. Análise crítica dos PCNs. Ini- } \\
\text { ciação à metodologia científica. Evento de Extensão em Ensino de } \\
\text { Ciências e Biologia em espaços não formais de ensino. Mostra do } \\
\text { Laboratório de Ensino em Ciências e Biologia. Temas especiais: } \\
\text { "Prevenção e combate ao uso de drogas" e outros. }\end{array}$ & $102 \mathrm{~h}$ \\
\hline $\begin{array}{l}\text { Laboratório de Ensino de } \\
\text { Ciências e Biologia III }\end{array}$ & $\begin{array}{l}\text { Contextualização do conhecimento disponibilizado nas disciplinas } \\
\text { da } 3^{\text {a }} \text { série do curso. Desenvolvimento de habilidades e competên- } \\
\text { cias relativas ao trabalho docente. Atividades de ação-reflexão-ação } \\
\text { na prática educativa diante das atividades propostas pelas discipli- } \\
\text { nas específicas. Metodologia do trabalho científico: projeto de pes- } \\
\text { quisa, métodos e técnicas de pesquisa, diferentes modalidades de } \\
\text { eventos científicos. Mostra do Laboratório de Ensino em Ciências e } \\
\text { Biologia. Temas especiais: "Educação das Relações Étnico-Raciais" } \\
\text { e outros. }\end{array}$ & $102 \mathrm{~h}$ \\
\hline $\begin{array}{l}\text { Laboratório de Ensino de } \\
\text { Ciências e Biologia IV }\end{array}$ & $\begin{array}{l}\text { Contextualização do conhecimento disponibilizado nas disciplinas } \\
\text { da } \text { 4}^{a} \text { série do curso. Desenvolvimento de habilidades e competên- } \\
\text { cias relativas ao trabalho docente. Atividades de ação-reflexão-a- } \\
\text { ção na prática educativa diante de projetos de trabalhos vinculados } \\
\text { às disciplinas específicas. Metodologia do trabalho científico: artigo } \\
\text { científico, normas e elaboração de currículo. } \\
\text { Mostra do Laboratório de Ensino em Ciências e Biologia. Temas espe- } \\
\text { ciais: "Ensino de História e Cultura Afro-brasileira e Africana" e outros. }\end{array}$ & $102 \mathrm{~h}$ \\
\hline Didática & $\begin{array}{l}\text { Reflexões sobre educação e o trabalho docente na escola. A didáti- } \\
\text { ca como área de saber voltada aos processos de ensino-aprendiza- } \\
\text { gem e seu papel na formação do professor. Organização do trabalho } \\
\text { pedagógico no cotidiano escolar: o planejamento educacional, seus } \\
\text { níveis e elementos. Avaliação do processo ensino-aprendizagem. }\end{array}$ & $68 \mathrm{~h}$ \\
\hline
\end{tabular}

Fonte: PPC-LicBio, 2015. 
$\mathrm{Na}$ análise comparada e qualitativa do conteúdo dos temas presentes nas ementas das disciplinas de Laboratório de Ensino de Ciências e Biologia I, II, III e IV, sinaliza-se para a potencialidade e a pertinência de temáticas relacionadas a prevenção e combate a drogadição, educação das relações étnico-raciais, ensino de história e cultura afro-brasileira e africana, o que atende as especificações das Diretrizes Curriculares Nacionais (DCNs) para a Educação das Relações Étnico-Raciais e para o Ensino de História e Cultura Afro-Brasileira e Africana, conforme o Parecer CNE/ CP 003/2004 (BRASIL, 2004a) e a Resolução CNE/CP nº. 001/2004 (BRASIL, 2004b).

Também se observa grande semelhança entre as ementas das disciplinas de Laboratório de Ensino de Ciências e Biologia, o que aponta para lacunas quanto ao delineamento do perfil profissional a ser formado, que professor se deseja formar, haja vista que as disciplinas específicas para a formação desse professor apresentam-se de forma generalizada, de acordo com as ementas analisadas.

Ressalta-se, ainda, que as disciplinas de Laboratório de Ensino de Ciências e Biologia correspondem a 408 horas da carga horária total do curso, a qual se insere nas 459 horas da Prática como Componente Curricular (PCC), conforme o PPC-LicBio, Currículo no 3 de 2009, apresenta:

A prática como componente curricular será vivenciada ao longo do curso num total de 459 (quatrocentas e cinquenta e nove) horas, embora esteja inserida como disciplina de Formação Básica Geral esta deve permear todo o processo de formação do professor numa perspectiva interdisciplinar contemplando dimensões teóricas e práticas, configurando-se através do Projeto Articulador da série, aprovado pelo Colegiado do Curso.

Com a iniciativa de construir e fortalecer a identidade do professor, as DCNs para a Formação de Professores da Educação Básica, tanto as de 2002 como as de 2015, apresentam a PPC como 400 horas de prática a serem vivenciadas no decorrer da graduação, considerando-se que "a prática, na matriz curricular, não poderá ficar reduzida a um espaço isolado, que a restrinja ao estágio, desarticulado do restante do curso", e que "a prática deverá estar presente desde o início do curso e permear toda a formação do professor" (TOLENTINO; OLIVEIRA; SOUZA, 2014).

No entanto, focalizar 408 horas em disciplinas apresentadas como integradoras, no caso do PPC-LicBio analisado, exige a inserção de inúmeras temáticas que possibilitem a formação integral do professor de Biologia, principalmente para suprir algumas lacunas, as quais não estão presentes nas ementas apresentadas, como: as discussões epistemológicas na formação do professor de ciências; história e a filosofia das ciências, o estudo das relações ciência, tecnologia e sociedade; divulgação científica, didática das ciências e interlocuções com os conhecimentos específicos do curso, entre outros conteúdos. Auxiliam esta análise as considerações de Manrique e Perentelli, quando afirmam: 
O princípio metodológico da prática como componente curricular não se resume na discussão de dimensão prioritária, entre teoria e prática, na formação do professor. Propõe pensar no processo de construção de sua autonomia intelectual: o professor além de saber e de saber fazer deve compreender o que fazer (2008, p. 11676).

Observa-se como lacuna a questão da Metodologia Científica nas ementas, pois, na primeira série do curso, o acadêmico entra em contato com a Iniciação à Metodologia Científica com visitas técnicas; na segunda série, apresenta-se apenas o tema "Iniciação à Metodologia Científica", sem ser delineada a forma como será elaborada essa iniciação; na terceira série, o acadêmico terá contato com construção de projetos, métodos e técnicas de pesquisa; na quarta série, trabalha-se a metodologia do trabalho científico, com a construção do artigo científico, normas e elaboração do currículo, não especificando ser o estudo das teorias do currículo, ou a construção do currículo na educação básica, ou a elaboração do curriculum vitae para inserção no mercado de trabalho, haja vista ser a quarta série a última etapa do acadêmico em formação inicial.

Essas lacunas sinalizam para problemas emergentes, como:

a) centraliza-se a discussão no fato de o acadêmico entrar em contato com a construção e as possíveis discussões mais efetivas de artigos e a construção de artigos científicos na última série do curso;

b) déficits relacionados à divulgação científica e à construção crítica do fazer científico, pois o contato do licenciado com o estudo pela pesquisa na formação docente possibilita o "desenho" da imagem adequada do que é a construção do conhecimento científico e suas implicações epistemológicas;

c) ausência dos estudos sobre ciência-tecnologia-sociedade; educação em saúde; pesquisa em educação em ciências; linguagem e escrita na educação em ciências; entre outras temáticas muito caras à área de educação em ciências e biologia, o que caracteriza um currículo liofilizado e com a ausência das discussões contemporâneas e de grande importância para a área.

Nesse sentido, o estudo de Gil Pérez et al. (2001) apresenta a importância de o professor de ciências ter adquirido em sua formação inicial uma imagem adequada da construção do conhecimento científico e enfatiza o dualismo entre a transmissão de conhecimentos científicos e a compreensão epistemológica do fazer científico:

Poder-se-ia argumentar que essa dissonância não é importante, pois não impediu os docentes de desempenharem a tarefa de transmissores de conhecimentos científicos (uma das funções sociais que lhes foi "encomendada"). No entanto, as limitações de uma educação científica centrada na mera transmissão de conhecimentos - limitações postas em relevo por uma abundante literatura, recolhida em boa medida nos Handbooks já publicados (Gabel, 1994; Fraser e Tobín, 1998; Perales e Cañal, 2000), deram origem a investigações que evidenciaram as concepções epistemológicas inadequadas e mesmo incorretas como um dos principais obstáculos 
aos movimentos de renovação da Educação em Ciência/Didática das Ciências (Bell e Pearson, 1992; Furió, 1994; Cachapuz, 1995a; Désautels e Larochelle, 1998 a e b). Assim se compreendeu que "toda a estratégia pedagógica adquire sentido e importância em função, entre outros factores, da opção epistemológica do seu autor" (Désautels et al., 1993). Este fato transformou o estudo das referidas concepções numa importante linha de investigação [...] (2001, p. 126).

Ressaltam-se, nas considerações de Gil Pérez et al. (2001), os "movimentos de renovação da educação em ciência/didática das ciências" diante das funções sociais "encomendadas aos professores de ciências de serem apenas transmissores de conhecimentos prontos, funções sociais, estas que podem ser entendidas como os 'pressupostos e valores' historicamente configurados na trama cultural, política e social que ecoam no currículo" (SACRISTÁN, 2000, p. 17).

Dessa forma, analisa-se a ementa da disciplina de Didática, com o intuito de identificar as aproximações da concepção de didática expressa no ementário com o movimento de renovação da educação em ciência/didática das ciências, apresentado por Gil Pérez et al. (2001). A ementa de Didática do PPC-LicBio apresenta a seguinte descrição:

Reflexões sobre educação e o trabalho docente na escola. A didática como área de saber voltada aos processos ensino-aprendizagem e seu papel na formação do professor. Organização do trabalho pedagógico no cotidiano escolar: o planejamento educacional, seus níveis e elementos. Avaliação do processo ensino-aprendizagem.

A análise qualitativa do conteúdo da ementa supracitada apresenta perfeitamente os temas e conteúdos pertinentes ao coletivo de pensamento da didática geral, no entanto, percebem-se lacunas no tocante ao processo de ensino e aprendizagem direcionado para as ciências da natureza, neste caso, para as Ciências Biológicas, situação que pode ser explicada por Sacristán, quando afirma:

O discurso em didática sobre a prática escolar se desenvolveu fragmentando o processo global do ensino-aprendizagem. Em primeiro lugar, desligando conteúdos de métodos, ensino de aprendizagem, fenômenos de aula em relação aos contextos nos quais se produzem, decisões técnico-pedagógicas de decisões políticas e determinantes exteriores à escola e à aula, etc. Em segundo lugar, por depender de determinadas tecnologias de pesquisa pouco propensas à compreensão da unidade que se manifesta na prática entre todos esses aspectos (2000, p. 47).

Nesse sentido, faz-se necessário estabelecer o currículo proposto como um configurador da prática ao superar as fragmentações estabelecidas no processo histórico. As discussões em torno da didática não se esgotam nesta análise, no entanto, a partir dos dados analisados e do referencial teórico de Fleck, pode-se sinalizar que, para além da disciplina de Didática, com 68 horas, seria de grande importância a inserção da disciplina de Didática das Ciências Biológicas, para que o licenciando, fundamentado nas discussões da didática geral, conforme a ementa 
propõe, possa aprofundar as discussões em torno do ensino de ciências em uma segunda disciplina de didática específica para a metodologia do ensino de ciências.

Entretanto, o currículo apresenta as disciplinas de Laboratório de Ensino de Ciências e Biologia I, II, III e IV, que teoricamente poderiam ser responsáveis pelas reflexões em didática das Ciências Biológicas, no entanto, as ementas dessas disciplinas apenas contemplam os Parâmetros Curriculares Nacionais para a área de Ciências da Natureza na $2^{a}$ série do curso, depois, ocupam-se de discussões extensionistas, de metodologia do trabalho científico, temas transversais e de cunho integrador dos conteúdos específicos. Isso é potencializado no estudo apresentado por Tolentino, Oliveira e Souza (2014), quando afirmam a instabilidade da identidade da PCC no curso de licenciatura e, por conseguinte, concepções "turvas" sobre a finalidade da disciplina de Laboratório de Ensino de Ciências e Biologia I, II, III e IV na formação do professor de ciências.

Nessa perspectiva, na análise das disciplinas de formação básica geral do PPC-LicBio, é possível indicar o coletivo de pensamento da didática geral; e, quanto ao possível coletivo de pensamento do ensino de ciências, conclui-se certa instabilidade quanto ao círculo esotérico de especialistas que constituíram o ementário das disciplinas responsáveis pelas discussões em torno de ensino e educação em ciências.

As disciplinas de formação básica geral apresentam diversos elementos para a discussão, no entanto, percebe-se que, com os subsídios das reflexões da didática e do ensino de ciências, faz-se necessário compreender como se configuram os conteúdos das disciplinas de formação específica profissional e em quais coletivos de pensamento se estratificam.

As DCNs para os cursos de Ciências Biológicas (Resolução CNE/CES nº 007/2002; Parecer CNE/CES nº. 1.301/2001) apresentam os conteúdos básicos para a formação do licenciado e do bacharel em Ciências Biológicas, organizando os conteúdos da seguinte forma:

BIOLOGIA CELULAR, MOLECULAR E EVOLUÇÃO: Visão ampla da organização e interações biológicas, construída a partir do estudo da estrutura molecular e celular, função e mecanismos fisiológicos da regulação em modelos eucariontes, procariontes e de partículas virais, fundamentados pela informação bioquímica, biofísica, genética e imunológica. Compreensão dos mecanismos de transmissão da informação genética, em nível molecular, celular e evolutivo.

DIVERSIDADE BIOLÓGICA: Conhecimento da classificação, filogenia, organização, biogeografia, etologia, fisiologia e estratégias adaptativas morfo-funcionais dos seres vivos.

ECOLOGIA: Relações entre os seres vivos e destes com o ambiente ao longo do tempo geológico. Conhecimento da dinâmica das populações, comunidades e ecossistemas, da conservação e manejo da fauna e flora e da relação saúde, educação e ambiente. 
FUNDAMENTOS DAS CIÊNCIAS EXATAS E DA TERRA: Conhecimentos matemáticos, físicos, químicos, estatísticos, geológicos e outros fundamentais para o entendimento dos processos e padrões biológicos.

FUNDAMENTOS FILOSÓFICOS E SOCIAIS: Reflexão e discussão dos aspectos éticos e legais relacionados ao exercício profissional. Conhecimentos básicos de: História, Filosofia e Metodologia da Ciência, Sociologia e Antropologia, para dar suporte à sua atuação profissional na sociedade, com a consciência de seu papel na formação de cidadãos (BRASIL, 2002, p. 5-6).

O PPC-LicBio atende a essa normativa classificando as disciplinas como de formação específica profissional, conforme a Figura 3:

Figura 3 - Disciplinas de formação específica profissional do PPC-LicBio

\begin{tabular}{|c|c|c|}
\hline \multicolumn{3}{|c|}{ DISCIPLINAS DE FORMAÇÄO ESPECÍFICA PROFISSIONAL } \\
\hline 3 & Fisica & 3.1 - Física Aplicada às Ciências Biológicas \\
\hline 4 & Bioquimica & 4.1 - Bioquímica \\
\hline 5 & Química & 5.1 - Química Geral e Orgânica \\
\hline 6 & Geografia & $\begin{array}{l}\text { 6.1 - Geografia Fisica Aplicada } \\
6.2 \text { - Geologia } \\
\text { 6.3 - Paleontologia } \\
6.4 \text { - Astronomia para Biologia }\end{array}$ \\
\hline 7 & Estatistica & 7.1 - Bioestatistica \\
\hline 8 & Biofisica & 8.1 - Biofísica \\
\hline 9 & Morfologia & $\begin{array}{l}9.1 \text { - Anatomia Humana } \\
9.2 \text { - Biologia Celular } \\
9.3 \text { - Embriologia } \\
9.4 \text { - Histologia Geral }\end{array}$ \\
\hline 10 & Fisiologia & 10.1 - Fisiologia Humana \\
\hline 11 & Botânica & $\begin{array}{l}\text { 11.1 - Diversidade e Evolução Vegetal } \\
\text { 11.2 - Fisiologia Vegetal } \\
\text { 11.3 - Morfoanatomia Vegetal }\end{array}$ \\
\hline 12 & Ecologia & 12.1 - Ecologia Geral \\
\hline 13 & Saúde Coletiva & 13.1 - Saúde Coletiva \\
\hline 14 & Parasitologia & 14.1 - Parasitologia Humana \\
\hline 15 & Microbiologia & 15.1 - Microbilologia \\
\hline 16 & Imunologia & 16.1 - Imunologia \\
\hline 17 & Genética & $\begin{array}{l}17.1 \text { - Evolução Biológica } \\
17.2 \text { - Genética Geral }\end{array}$ \\
\hline 18 & Zoologia & $\begin{array}{l}18.1 \text { - Zoologia de Invertebrados I } \\
18.2 \text { - Zoologia de Invertebrados II } \\
\text { 18.3 - Zoologia de Vertebrados }\end{array}$ \\
\hline
\end{tabular}

Fonte: PPC-LicBio, 2015. 
Na Figura 3, observam-se os conteúdos básicos das DCNs para os cursos de Ciências Biológicas como componentes de formação específica profissional dos professores de Biologia, ou seja, o conteúdo de Biologia propriamente dito. À luz da epistemologia de Fleck, é possível considerá-los como possíveis coletivos de pensamento, pois apresentam características de "comunidades estáveis (ou relativamente estáveis) de pensamento, assim como outras comunidades organizadas, cultivam um certo fechamento na forma e no conteúdo" (FLECK, 2010, p. 155).

Além das disciplinas de formação específica e profissional, têm-se no PPC-LicBio as disciplinas de diversificação ou aprofundamento, conforme a Figura 4:

Figura 4 - Disciplinas de diversificação e aprofundamento do PPC-LicBio

\begin{tabular}{|c|c|c|}
\hline \multicolumn{3}{|c|}{ DISCIPLINAS DE DIVERSIFICAÇÄO OU APROFUNDAMENTO } \\
\hline 10 & Fisiologia & $\begin{array}{l}\text { 10.2 - Prảtica de Fisiologia para o Ensino de } \\
\text { Ciências Biológicas }\end{array}$ \\
\hline 11 & Botånica & 11.1 - Biomas do Paraná \\
\hline 12 & Ecologia & 12.2 - Gestão e Educação Ambiental \\
\hline 15 & Microbiologia & $\begin{array}{l}\text { 15.2 - Microbiologia para o Ensino de Ciẽncias e } \\
\text { Biologia }\end{array}$ \\
\hline 17 & Genètica & 17.3 - Tópicos Especiais em Genética \\
\hline 18 & Zoologia & $\begin{array}{l}\text { 18.4 - Animais Peçonhentos } \\
\text { 18.5 - Plantas Medicinais }\end{array}$ \\
\hline 19 & Geociẽncias & 19.1 - Astrobiologia \\
\hline 20 & Educaçāo Sexual & 20.1 - Biologia da Sexualidade e Adolescēncia \\
\hline
\end{tabular}

Fonte: PPC-LicBio, 2015.

Dentre as disciplinas de diversificação ou aprofundamento, com 68 horas cada uma, o acadêmico deverá escolher apenas uma para cursar no decorrer do curso. Sendo assim, inicia-se um delineamento dos possíveis coletivos de pensamento dos conteúdos básicos presentes nas DCNs para os cursos de Ciências Biológicas, com os possíveis coletivos de pensamento das disciplinas de formação específica profissional do PPC-LicBio, que são estratificações das diretrizes (BRASIL, 2001, 2002), permitindo-nos compreender a possível circulação de conhecimentos e práticas entre os coletivos de pensamento da formação específica e profissional, conforme o fluxograma na Figura 5: 
Figura 5 - Possíveis coletivos de pensamento das disciplinas de formação específica profissional do PPC-LicBio estratificados das DCNs dos cursos de Ciências Biológicas

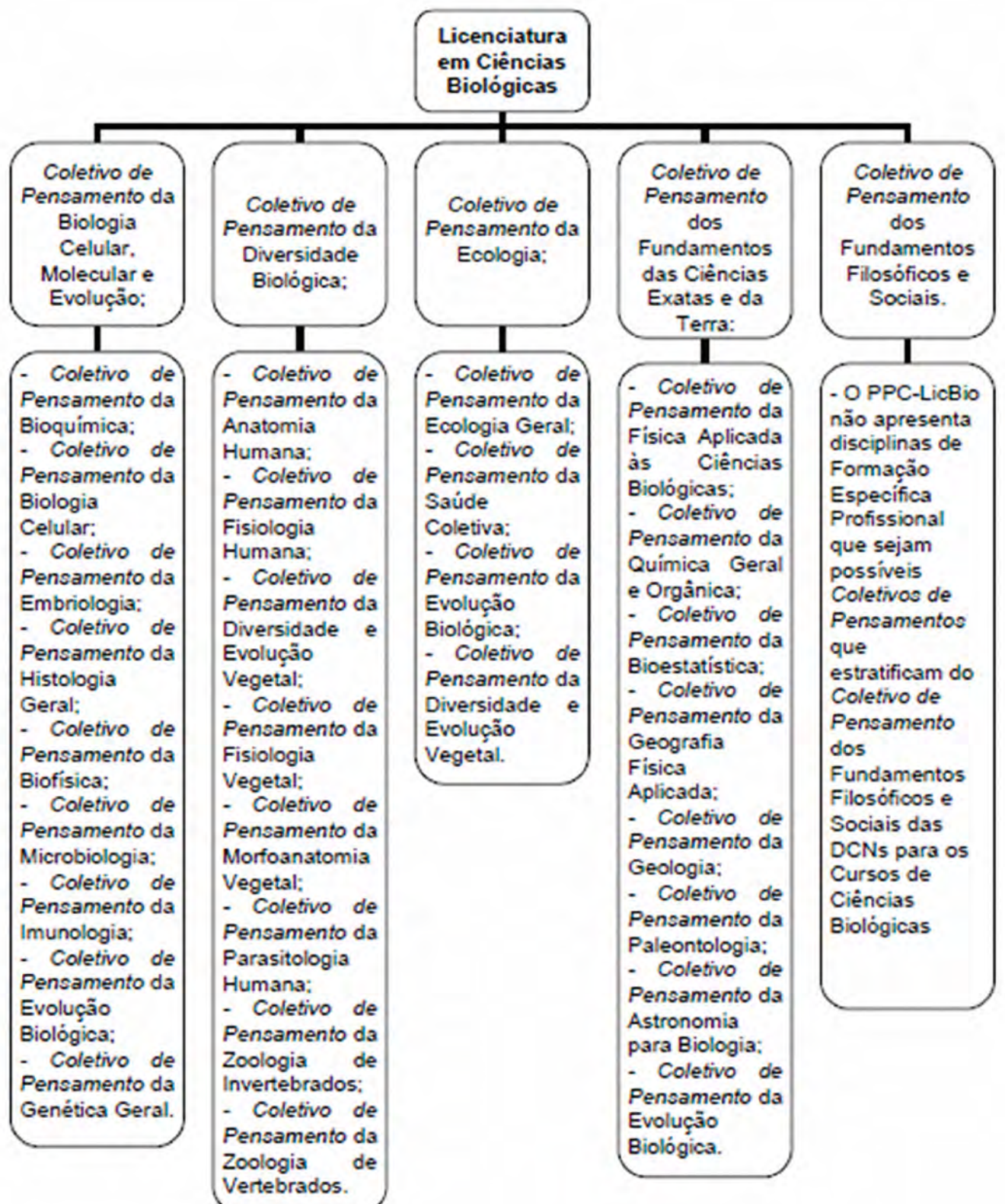

Fonte: PPC-LicBio, 2015. 
Muitos dos coletivos de pensamento apresentados na Figura 3 podem ser organizados em demais coletivos, por ocasião das especificidades de cada área, no entanto, indicam-se os possíveis coletivos presentes no PPC-LicBio, que estão em consonância com os coletivos das DCNs para os cursos de Ciências Biológicas.

Nesse panorama, evidencia-se o fato de o coletivo de pensamento da evolução biológica, por exemplo, estar compartilhando conhecimentos e práticas com os coletivos de pensamento da Ecologia e dos fundamentos das Ciências Exatas e da Terra, na medida em que práticas e conhecimentos específicos da evolução biológica contribuem para uma maior compreensão dos conhecimentos em Ecologia e Ciências Exatas e da Terra.

Sendo assim, identificam-se as circulações de conhecimentos e práticas do círculo esotérico do coletivo de pensamento da evolução biológica para o interior do círculo esotérico do coletivo das Ciências Exatas e da Terra, especificamente para os coletivos de pensamento da Paleontologia, da Astronomia aplicada à Biologia e da Geologia, os quais são exotéricos ao coletivo de pensamento da evolução biológica.

Entretanto, o tráfego entre os coletivos, no exemplo citado, traz contribuições da evolução biológica como eixo integrador para a compreensão da evolução geológica da terra, bem como dos registros fósseis da paleontologia que apresentam dados empíricos, que, muitas vezes, legitimam as teorias e as concepções evolutivas.

Por exemplo, os movimentos de circulações inter e intracoletivas de conhecimentos e práticas também se dão nas relações entre a Biologia Celular e tantas outras áreas das Ciências Biológicas que compartilham dos conhecimentos de Biologia Celular, bem como das relações entre Imunologia, Microbiologia e Parasitologia, que também apresentam tráfego intenso de compartilhamento de conhecimentos e práticas.

Ressaltando-se que, neste artigo, essas circulações de conhecimentos e práticas estão dadas no âmbito da licenciatura em Ciências Biológicas, no entanto, é possível também estabelecer relações entre as circulações da grande área de Ciências Biológicas e das Ciências da Saúde de modo geral, ou seja, os conhecimentos básicos das Ciências Biológicas são essenciais para o desenvolvimento dos conhecimentos aplicados nos âmbitos das formações em Farmácia, Enfermagem, Medicina, Odontologia, entre outros cursos das Ciências da Saúde.

Nesse sentido, sobre a leitura fleckiana das relações entre o currículo do curso de licenciatura em Ciências Biológicas, as circulações inter e intracoletivas de conhecimentos e as práticas na formação do professor de Biologia, as palavras de Sacristán auxiliam-nos a compreender o processo de construção coletiva do currículo: 
Desde um enfoque processual ou prático, o currículo é um objeto que se constrói no processo de configuração, implantação, concretização e expressão de determinadas práticas pedagógicas e em sua própria avaliação, como resultado das diversas intervenções que nele se operam. Seu valor real para os alunos, que aprendem seus conteúdos, depende desses processos de transformação aos quais se vê submetido (2000, p. 101).

A afirmação do autor também permite uma interpretação fleckiana, observando as relações que se estabelecem no estado de conhecimento, no qual a realidade objetiva e o sujeito relacionam-se por meio dos acoplamentos ativos e passivos, nos quais o conhecimento se constrói.

Logo, a construção do currículo também se dá a partir das influências do contexto, o estado do conhecimento que implica as concepções dos coletivos e estilos de pensamento dos especialistas que balizam a construção do currículo, o qual passa a ser disseminado para o círculo exotérico e torna-se vigente (harmonia de ilusões) ou, com o tempo, desperta as possíveis complicações que irão direcionar para a emergência de um novo fato científico, ou seja, um novo currículo para o enfrentamento das complicações.

Ainda, diante da análise da Figura 3, outro dado relevante consiste na ausência de disciplinas no PPC-LicBio que contemplem o coletivo de pensamento dos fundamentos filosóficos e sociais, propostos pelas DCNs para os cursos de Ciências Biológicas, provavelmente, os conteúdos correspondentes a tal coletivo são identificados como disciplinas de formação básica geral.

No entanto, ao classificar disciplinas que disseminam o coletivo de pensamento da educação como disciplinas que disseminam o coletivo de pensamento dos fundamentos filosóficos e sociais, embora apresentem algumas aproximações entre elas, constatam-se distanciamentos epistemológicos, ou seja, são coletivos de pensamento distintos que compartilham conhecimentos e práticas.

\section{Considerações finais}

Os resultados desta pesquisa apontam para a existência de possíveis coletivos de pensamento que estão presentes na formação dos professores de Biologia, os quais se movimentam no processo formativo dos professores por meio da instauração, da extensão e da transformação dos estilos de pensamento no interior dos coletivos e, por consequência, dos próprios coletivos de pensamento; e a importância das complicações no processo de emergência de um novo fato científico e para a instauração de um novo estilo de pensamento.

Considera-se que o conhecimento científico, construído coletivamente e situado socio-historicamente, carrega valores subjacentes atrelados à rigorosidade 
teórica e conceitual, e os conhecimentos e as práticas específicas da área e das subáreas das Ciências Biológicas são compartilhados reciprocamente nos círculos exotéricos e esotéricos.

Pontuam-se, também, as lacunas presentes nas disciplinas que compõem a área de Educação em Ciências no PPC-LicBio analisado, o que indica a necessária reflexão acerca de que professor busca-se formar e da importância da presença das discussões relacionadas ao ensino para a efetivação da identidade de curso de licenciatura, e não de um bacharelado disfarçado de licenciatura.

Compreende-se que a organização curricular da licenciatura em Ciências Biológicas, bem como das outras licenciaturas, delineia os trajetos curriculares pelos quais os licenciados são formados e, de certa forma, é determinante na construção do perfil profissional dos futuros professores.

Por fim, evidencia-se a efetividade da epistemologia de Fleck para uma maior compreensão da importância da organização curricular na formação dos professores e das implicações epistemológicas que trafegam, muitas vezes de modo oculto, no interior dos coletivos de pensamentos que compõem o currículo.

\section{Referências}

ALVES, Daniel C. Análise e crítica do conceito de ciência normal de Thomas Kuhn e sua filosofia da ciência de viés histórico. 2012. Dissertação (Mestrado em Filosofia) - Programa de Pós-Graduação em Filosofia, Universidade Federal de Santa Catarina, Florianópolis, SC, 2012.

BRASIL. Ministério da Educação. Conselho Nacional de Educação. Parecer sobre as Diretrizes Curriculares Nacionais para os Cursos de Ciências Biológicas. Parecer CNE/CES nº. 1.301/2001. Brasília, DF: MEC/CNE, 2001.

. Diretrizes Curriculares Nacionais para os Cursos de Ciências Biológicas. Resolução n⿳o. 007, de 2002. Brasília, DF: MEC/CNE, 2002.

Diretrizes Curriculares Nacionais para a Educação das Relações Étnico-Raciais e para o Ensino de História e Cultura Afro-Brasileira e Africana. Parecer CNE/CP 003/2004. Brasília, DF: MEC/CNE, 2004a.

Diretrizes Curriculares Nacionais para a Educação das Relações Étnico-Raciais e para o

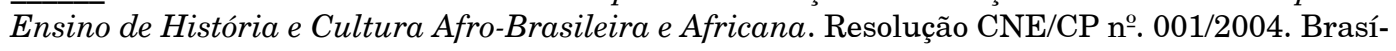
lia, DF: MEC/CNE, 2004b.

CUTOLO, Luiz Roberto A. Estilo de pensamento em educação médica um estudo do currículo do curso de graduação em Medicina da UFSC. 2001. Tese (Doutorado em Educação) - Programa de Pós-Graduação em Educação, Universidade Federal de Santa Catarina, Florianópolis, SC, 2001.

DA ROS, Marco Aurélio. Estilos de pensamento em educação médica: um estudo da produção da FSP-USP e ENSPFIOCRUZ entre 1948 e 1994, a partir de epistemologia de Ludwik Fleck. 2000. Tese (Doutorado em Educação) - Programa de Pós-Graduação em Educação, Universidade Federal de Santa Catarina, Florianópolis, SC, 2000. 
DELIZOICOV, Nadir C.; CARNEIRO, Maria Helena da S.; DELIZOICOV, Demétrio. O movimento do sangue no corpo humano: do contexto da produção do conhecimento para seu ensino. Ciência \& Educação, Bauru, v. 10, n. 3, p.443-460, 2004.

DELIZOICOV, Demétrio et al. Sociogênese do conhecimento e pesquisa em ensino: contribuições a partir do referencial fleckiano. Caderno Brasileiro de Ensino de Física, Florianópolis, v. 19, número especial, p. 52-69, jun. 2002.FLECK, Ludwik. Gênese e desenvolvimento de um fato científico. Belo Horizonte: Fabrefactum, 2010.

FLICK, Uwe. Introdução à pesquisa qualitativa. 3. ed. Porto Alegre: Artmed, 2009.

GIL PÉREZ, Daniel et al. Para uma Imagem não deformada do Trabalho Científico. Ciência \& Educação, Bauru, v. 7, n. 2, p. 125-153, 2001.

GONÇALVES, Fábio P.; MARQUES, Carlos A.; DELIZOICOV, Demétrio. O desenvolvimento profissional dos formadores de professores de química: contribuições epistemológicas. Revista Brasileira de Pesquisa em Educação em Ciências, Belo Horizonte, v. 7, n. 3, p. 51-67, 2007.

MANRIQUE, Ana Lúcia; PERENTELLI, Leia Fernandes. Um estudo sobre a prática como componente curricular em cursos de licenciatura em Matemática. In: CONGRESSO NACIONAL DE EDUCAÇÃO, 8, 2008, Curitiba, PUC-PR. Anais... Curitiba: Champagnat, 2008. p. 11675-11688.

MELZER, Ehrick E. M. Reflexões em Ludwik Fleck: a aplicabilidade de seus conceitos no ensino de Ciências. In: CONGRESSO NACIONAL DE EDUCAÇÃO - EDUCERE, 1; SEMINÁRIO INTERNACIONAL DE REPRESENTAÇÕES SOCIAIS, SUBJETIVIDADE E EDUCAÇÃO SIRSSE, 8, 2011, Curitiba, PUC-PR. Anais... Curitiba: PUC-PR, 2011. p. 6776-6789.

PFUETZENREITER, Márcia R. Epistemologia de Ludwik Fleck como referencial para a pesquisa nas Ciências Aplicadas. Revista Episteme, Porto Alegre, n. 16, p. 111-135, jan./jun. 2003.

PIAGET, Jean; GARCÍA, Rolando. Psicogênese e história das ciências. Petrópolis: Vozes, 2011.

SACRISTÁN, José G. O currículo: uma reflexão sobre a prática. 3. ed. Porto Alegre: Artmed, 2000 .

TOLENTINO, Patricia C.; ROSSO, Ademir J. A identificação profissional de licenciandos em Ciências Biológicas na perspectiva epistemológica de Ludwik Fleck. Momento - Diálogos em Educação, Rio Grande, v. 20, n. 2, p. 9-18, 2011.

TOLENTINO, Patricia; OLIVEIRA, Luiz Antonio; SOUZA, Rodrigo D. A prática como componente curricular no processo formativo de professores de Ciências e Biologia: concepções e realidade. Revista de Ensino de Biologia da Associação Brasileira de Ensino de Biologia, Niterói, v. 7, p. 6079-6089, 2014. 